\title{
Discussing Controversial Issues in the Classroom
}

\author{
Michael Hand \& Ralph Levinson
}

Institute of Education, University of London

\begin{abstract}
Discussion is widely held to be the pedagogical approach most appropriate to the exploration of controversial issues in the classroom, but surprisingly little attention has been given to the questions of why it is the preferred approach and how best to facilitate it. Here we address ourselves to both questions. We begin by clarifying the concept of discussion and justifying it as an approach to the teaching of controversial issues. We then report on a recent empirical study of the Perspectives on Science AS-level course, focusing on what it revealed about aids and impediments to discussion of controversial ethical issues.
\end{abstract}

Keywords: discussion, controversial issue, ethics, disagreement

\section{Introduction}

A small but steady stream of publications on the teaching of controversial issues has been winding its way through the delta of educational literature for some three decades. These publications include a handful of authored and edited volumes (Carrington \& Troyna, 1988; Claire \& Holden, 2007; Stradling, Noctor \& Baines, 1984; Wellington, 1986), a series of journal articles (Dearden, 1981; Dewhurst, 1992; Gardner, 1984; Geddis, 1991; Hand, 2008a, 2007; Hess, 2004, 2002; Kelly, 1986; Levinson, 2006, 2001; Oulton et al., 2004a, 2004b; Solomon, 1992, 1990; Stenhouse, 1969; Thomas, 2000), and a range of practical guides and online resources for teachers (Oxfam, 2006; TeacherNet, 2006; LSDA, 2005; CitizEd, 2004; Citizenship Foundation, 2003; Runnymede Trust, 2003; CFE, 2002; QCA, 2001; DEA, 2001). Without exception, as far as we can tell, the contributors to this body of literature hold discussion to be the pedagogical approach most appropriate to the exploration of controversial issues in the classroom. Remarkably, however, they give little serious attention to the questions of what discussion is, why it is the preferred approach, and how best to facilitate it.

Of the 45 chapters in the four standard volumes, for example, only two devote more than a couple of lines to discussion. In the first of these, Jean Rudduck (1986) argues that 'the mode of inquiry in controversial areas should have discussion rather than instruction as its core' (p. 8), on the basis that discussion 'supports the interplay of various perspectives on a closely focused issue or task and permits individual members of the group to arrive at their own understanding in the light of evidence that has been critically 
examined' (p. 9). She goes on to provide a list of 'common problems' drawn up by teachers involved in the Humanities Curriculum Project, noting how discussion can be inhibited or derailed by students who are too dominant, too attention-seeking, too quiet or too dependent on the teacher (p. 12). In the second, Debra Myhill (2007) contends that 'discussion is an essential element of addressing controversial issues because potentially it gives every child a voice and, handled effectively, it opens up an awareness of the range of views available on a particular topic and is democratic because no-one controls the "right" answer' (p. 58). To facilitate productive discussion, she says, teachers must 'be very confident about the topic' and must 'be able to listen to children's responses and ask questions at key points which will help to move the debate on' (p. 59).

Among the journal articles, the most detailed treatments of discussion are to be found in Joan Solomon's $(1990,1992)$ reports on the Discussion of Issues in School Science (DISS) research project. Solomon, however, is more interested in describing and interpreting students' discussions than in justifying their use or offering guidance on their facilitation. Discussion of controversial scientific issues, she suggests, merits the attention of researchers because it is 'the commonest way we have of trying to assimilate and understand the latest developments in science and technology' (Solomon, 1990, p. 116); but that it is common does not show that it is pedagogically preferable to the alternatives. Perhaps the most interesting finding of the DISS research, for our purposes, was that students' discussions of controversial issues can be 'valuable in terms of the construction and exchange of moral and civic views' (Solomon, 1992, p. 431) and may thus advance the educational aim of producing 'an informed generation of new citizens who can take part in democratic decision making' (p. 442).

These are helpful first steps, but they hardly amount to a comprehensive treatment of the topic. If discussion is to be commended as the optimum pedagogy for teaching controversial issues, a good deal more needs to be said, both about the reasons for commending it and about the factors that tend to promote or obstruct it in the classroom. Here we address ourselves to both tasks. We begin by clarifying the concept of discussion and justifying it as an approach to the teaching of controversial issues. We then report on a recent empirical study of the Perspectives on Science AS-level course, focusing on what it revealed about aids and impediments to discussion of controversial ethical issues.

\section{The Case for Teaching Controversial Issues through Discussion}

In his careful and compelling book-length analysis of the concept of discussion and its use in educational contexts, David Bridges (1979) offers the following 'necessary and sufficient conditions for saying that people are engaged in the discussion of something':

a) they are putting forward more than one point of view upon a subject;

b) they are at least disposed to examine and be responsive to the different points of view put forward; with

c) the intention of developing their knowledge, understanding and/or judgment on the matter under discussion. (p. 16)

Discussions involve multiple points of view. A conversational exchange or a prose passage in which only one point of view is articulated does not count as a discussion. Where 
conversationalists express different opinions, or a writer considers more than one position on a matter, the first necessary condition of discussion is met.

The articulation of different points of view is not, however, sufficient for discussion. Discussants must also be receptive or responsive to opinions other than their own. To enter a discussion, says Bridges, is 'necessarily to bring to the presentation of different points of view not a completely open mind perhaps but at least some minimal disposition to understand, to appreciate and to be affected by the range of opinion which is presented' (pp. 15-16). It is not enough for people to be taking it in turns to rehearse entrenched and impervious views, as in a 'debate between rigidly opposed political adversaries' (p. 15): discussion requires that people are genuinely willing to listen to and learn from one another, and to change or modify their views in light of what they hear.

Bridges' third necessary condition, that discussants must be concerned with developing their knowledge, understanding or judgment, brings out the chief difference between a discussion and a conversation. Discussions are in this sense serious, 'whereas conversation and conversationalists may, and perhaps are conventionally expected to, address their subject lightly or indeed playfully' (p. 14). It is the desire to get to the truth of a matter, to get something right, that distinguishes discussion from more casual or frivolous human exchanges.

From these necessary and sufficient conditions of discussion, Bridges derives 'an important set of moral dispositions or principles' that must be shared 'at least to some measure' by participants in oral group discussion (as distinct from literary or solitary discussion). The dispositions required are reasonableness, peaceableness and orderliness, truthfulness, freedom, equality and respect for persons (pp. 21-3). This implies both that the quality of discussion in classrooms will depend in part on the degree to which students have acquired the necessary virtues, and, at the same time, that learning to participate in discussion may itself help students to develop these virtues.

Why is discussion the preferred method for teaching controversial issues? There are, we think, two basic reasons. First, discussion is peculiarly conducive to appreciative understanding of the different positions in a controversy and to empathy with those who hold them. It is easy enough to convey to students a theoretical understanding of what is at stake in a controversial issue by instructional or expository means; but it is hard to convey by these means a sense of the passion and sincerity with which rival views are held, of their plausibility and appeal in the context of different background assumptions, and of the ways in which they are intertwined with people's identities, affiliations and life experiences. Discussion, at least insofar as rival views are represented within the group, yields just this kind of appreciative understanding. For here students are no longer dealing abstractly with positions on a theoretical spectrum, but concretely with the deeply-held commitments of their friends and classmates. Stephen Brookfield and Stephen Preskill put it like this:

Ideas that are perceived as distanced or irrelevant when presented through a lecture come alive when we have to explore them through speech. Arguments that were abstract when read in a text grab our attention when spoken by a peer. Interpretations that might be skipped over when encountered outside the classroom cannot be dismissed when proposed by a colleague. (Brookfield \& Preskill, 1999, p. 22) 
Knowing the arguments for and against abortion is one thing. Engaging attentively and open-mindedly with someone who takes a view on abortion diametrically opposed to one's own is quite another.

And it is not only views contrary to their own that students come to understand more deeply through discussion. Their own views, too, come to be seen in a more comprehensive light as the assumptions and values that underpin them are gradually made manifest. 'Our most influential assumptions,' observe Brookfield and Preskill, 'are too close to us to be seen clearly by an act of self-will'; but in the to and fro of discussion, 'students can serve as critical mirrors for each other, reflecting the assumptions they see in each other's positions' (p. 20).

The second basic reason for teaching controversial issues through discussion reverses the direction of justification: it is not just that discussion yields the most appreciative understanding of controversial issues, but that controversial issues afford the most promising opportunities for engaging students in discussion. Cultivating in students the ability and inclination to engage in discussion is itself an important educational goal, and one that can arguably only be achieved by means of the teaching of controversial issues.

Discussion plays a central role in many worthwhile activities, not least those concerned with the pursuit of truth. All major forms of inquiry put a premium on the free exchange of ideas, the attentiveness to divergent views and the scrutiny of opposing arguments that are constitutive of discussion. Insofar as we want to equip students for participation in these and other worthwhile activities, we must initiate them into the practice of discussion.

But this requirement presents us with a problem: the nature and purposes of educational institutions militate against the prospect of engaging students in genuine discussion. Bridges explains why:

Schools, universities and teachers are instituted at least in part to ... preserve, pass on and, marginally, to advance the accumulated wisdom of the ages. Necessarily, however, such a process of transmission is one which relies upon and proceeds through someone's 'say-so'. The 'teacher' in his many social forms saves us some of the time-consuming and perhaps futile labour of enquiry, saves us the search for validation and assists us in the selection of what as a priority we ought to know. (p. 63)

Educational institutions exist so that each generation does not have to start again from scratch. They exist to bring the young up to speed on the epistemic, artistic and technological achievements of their forebears, with a view to enabling them to make their own contributions to human knowledge and culture. Teachers are charged with selecting from and imparting to students 'the best which has been thought and said in the world' (Arnold, 1869, p. 6), a task for which they must be, and must be recognised to be, authorities on their subjects. The didactic dynamic of this 'process of transmission' is radically inconsistent with the exploratory dynamic of discussion.

Teachers persuaded of the importance of discussion have two options open to them. One is to use discussion-like interaction as a means of leading students to the knowledge they are charged with imparting. This, of course, is not discussion at all (though it often goes by that name in schools), but merely instruction-in-disguise. It consists not in 
discussants pursuing truth together in a spirit of receptivity to one another's ideas and insights, but in experts seeking to shape the thinking and correct the misconceptions of novices. Such disguised instruction not only fails to engage students in genuine discussion but also runs the risk of giving them a debased and distorted impression of what discussion is. There is, moreover, something straightforwardly dishonest about it:

... to ask a question as if it were a genuine enquiry when it is not, or to engage people in what purports to be a genuine enquiry, while actually manipulating the whole process to your own ends is to be at best covert and at worst downright dishonest. It is difficult to see how to defend such practice when there are perfectly practicable alternative patterns of behaviour open to one. (Bridges, 1979, p. 114)

The second option is for teachers to take their own expertise out of the equation by acting as a neutral chair of, rather than an active participant in, discussion. They may do this in the hope that their students will get to the truth of the matter under discussion, but they are not now manipulating the process to guarantee that outcome. This is an improvement on the first option, but a basic difficulty remains: the fact that the teacher is acknowledged to be an authority on the matter in hand deprives the students' discussion of its point. 'In logic and in practice,' writes Bridges, 'to perceive someone in a group as an authority upon that which the group seeks to advance its knowledge or understanding is to import a condition which negates the principles which make discussion purposeful or indeed intelligible' (p. 56). There is simply no credible reason for a group to discuss a question to which one among them already knows the answer. Once again, the element of artifice here threatens to undermine the effort to involve students in discussion.

The teaching of controversial issues offers a way out of this bind. To explain why, we must say a little more about the issues we are counting as controversial for the purposes of teaching. To teach something as controversial is to teach it as unsettled, to present it as a matter on which contrary views are or could be held; and we take it that teachers ought only to teach something in this way when 'contrary views can be held on it without those views being contrary to reason' (Dearden, 1981, p. 38; see also Hand, 2008a). That is to say, we endorse an epistemic rather than a behavioural criterion of controversiality. From the fact that a question happens to occasion dispute in some quarters, it does not follow that it should be taught as controversial: there may an entirely satisfactory and wellestablished answer to the question, of which some parties to the dispute are simply ignorant. Nor does the absence of dispute imply that an issue is settled: it may just be too remote from people's practical or theoretical concerns to generate strongly-held views. What matters, from an educational point of view, is not whether disagreement actually occurs, but whether it is epistemically warranted, whether more than one view on a matter is rationally defensible.

So understood, controversial issues are matters on which teachers are not authorities. Teachers will often have opinions on them, hopefully informed and considered ones, but their opinions do not have the status of knowledge. They know that other, equally reasonable and well-informed people hold contrary opinions and that the available evidence and argument can be construed in more ways than one. Regardless of how 
firmly they may be wedded to their opinions, they recognise that these matters are unsettled and there is scope for further intellectual work on them.

Controversial issues, then, are the one area of the curriculum in which teachers can engage students in genuine discussion, can join them in a collaborative, mutually attentive and responsive exploration of questions to which none of them knows the answer. There is no need here for the deception of instruction-in-disguise or the artifice of teachers declining to share the knowledge they possess; rather, teachers and students are full and equal participants in the communal discursive quest for understanding. Some of the most interesting work on collaborative classroom inquiry of this kind is to be found in the literature on Philosophy for Children (e.g. Cam, 1995; Lipman, 1988, 1991; McCall, 2009; Murris \& Haynes, 2000; Splitter \& Sharp, 1995), though it is in some ways unfortunate that the 'community of inquiry' method is so closely associated with the teaching of philosophy. There are, to be sure, many controversial philosophical issues; but not all philosophical questions should be taught as controversial (Hand, 2008b), and many controversial issues have nothing much to do with philosophy.

If initiating students into the practice of discussion is an important educational goal, it would be rash to pass up the rare opportunities for this that controversial issues afford. Not the least of the reasons for teaching controversial issues through discussion, then, is simply that we can.

\section{Some Helps and Hindrances to Discussion}

\section{The Empirical Study}

In 2007 we were commissioned to conduct a small-scale empirical study of some innovative aspects of the new Perspectives on Science (POS) AS level course in the history, philosophy and ethics of science. At that time POS was in its pilot phase and was offered by 26 secondary schools and further education colleges across the UK.

The first half of the POS course is devoted to developing students' analytical skills in relation to a range of questions and controversies with a scientific dimension. The second half requires students to carry out individual research projects in which they investigate the 'story' behind a question of their choosing, explore the historical, philosophical and ethical aspects of that question, and present the outcomes of their research both orally and in writing. Assessment of the course is based entirely on these oral and written presentations.

Throughout the course there is an explicit and pronounced emphasis on discussion. The directors of POS, John Taylor and Elizabeth Swinbank, justify this emphasis as follows:

In the POS course, discussion and debate are treated as integral to the learning process, not simply as 'add-ons' to spice up otherwise didactic performances by the teacher. The validity of this approach lies partly in the fact that, by their very nature, historical, philosophical and ethical questions are 'open'. They are the topic of an ongoing cultural discussion which calls for personal judgment 
and the development of reasonable points of view in a context where, by the nature of the questions, there is unlikely to be conclusive resolution. (Taylor \& Swinbank, 2007, p. 43)

The innovative aspects of POS we chose to explore in our study were the emphasis on discussion and debate and the assessment of students by means of individual research projects. In this article we present our findings as they relate to the question: what are the factors that help or hinder discussion in POS classes?

We used a mixed method research design combining survey questionnaires, semistructured interviews and classroom observations. The questionnaires were intended to yield a broad overview of teachers' and students' perspectives, the interviews to elicit more considered and nuanced points of view, and the observations to enable us to assess for ourselves the quality of, and the aids and impediments to, class discussion. We surveyed the entire population of teachers and students involved in POS in the 2006-07 and 2007-08 cohorts, with questionnaire return rates of between $60 \%$ and $70 \%$. Interviews and observations were conducted in four POS centres: an independent school, a state comprehensive school, a grammar school and a sixth form college. To supplement the observations we made in person, we invited the centres to video-record discussions and send us the recordings.

Quantitative questionnaire data was entered into a SPSS database in order to identify frequencies of and correlations between responses. Interview data, observation data and qualitative questionnaire data was coded, and key themes were identified, through an iterative process of reading and re-reading transcripts in light of emerging codes.

Voluntary informed consent was sought from all participants. Participants were given full information about the project and those selected for observation or interview had an opportunity to ask questions about the research. They were made aware that they were under no obligation to participate and that they had an unconditional right to withdraw. All participants were anonymised and all data collected was stored securely in passwordprotected electronic files.

\section{Research Findings}

Our data revealed four factors that tend to aid discussion: effective preparation, accessible topics, strong and diverse views among discussants, and appropriate facilitation. It also highlighted two moves sometimes made by students that tend to impede discussion: the that's-just-what-I-believe move and the that's-what-my-religion-says move. We describe each of these aids and impediments in turn.

\section{Effective Preparation}

Many of the students and teachers we spoke to emphasised the importance of thorough preparation for discussion. There was general agreement, borne out in the quality of the discussions we observed, that discussion is significantly enhanced when participants are equipped with (i) the ability to analyse and evaluate arguments and (ii) relevant background information on the topic of inquiry. 
Training in the analysis of arguments is a prominent feature of POS and was mentioned by several students. One reported that 'what I found particularly interesting in the first year was how an argument is developed, so we look at premises, and all that, so it was more about how to think about arguing'. Another gave a detailed account of the method he had been taught for identifying the structure of arguments in newspaper articles:

It's like a breakdown, there's a whole text you get from the newspaper and you take out certain words, you highlight certain words and you break them down then you start to reduce the argument to a core box so you dissolve all the paraphernalia of the text and you get what's actually there and it just makes it a lot easier. It's so good doing that. You get certain topics, so his idea, his general beliefs, and then what objections we have to that and then what arguments we have to that. It's a system that works really well to approach pretty much anything.

While it was recognised by participants that analytical and argumentative skills could be refined in and through discussion, what they emphasised was the value of explicit instruction in these skills prior to engaging in discussion.

The necessity for background information on topics of inquiry was also acknowledged by teachers and students alike. It was clear to all that some prior knowledge of relevant facts and theories was a prerequisite of fruitful discussion. But the teachers making this point added two important caveats. First, they did not want the provision of background information to cast them too much in the role of resident expert: 'there are times when maybe we're sharing ignorance together but I think that's useful for students to realise'. Second, they were alert to the danger of information overload, of impeding the flow of discussion by overwhelming students with large and indigestible bodies of knowledge:

That's a real skill in teaching. I've seen lessons (other than in POS) where the teacher saturates the students with facts, where the more facts they get the less able they are to have the discussion and make the value judgments and the less able they are to extract the information around the topic.

\section{Accessible Topics}

A notable feature of the discussions we observed was that all but one of them were explicitly focused on issues in the ethics, as distinct from the history or philosophy, of science. The ethical issues we saw being discussed included xenotransplantation, organ donation, genetic engineering, abortion and capital punishment. These ethical discussions were marked by high levels of student participation and stayed reasonably well focused on the issue in hand.

The one non-ethical discussion we observed was about a newspaper article reporting some research on the degree to which people's lives follow genetically predetermined paths. The article was intended by the teacher to prompt discussion of the philosophical problem of free will and determinism. In fact the students appeared reluctant to discuss this problem, even when given some fairly strong steers by the teacher, preferring to focus on questions about the methodology of the reported research.

The principal difference between the ethical issues on one hand and the philosophical issue on the other was accessibility to the students. The ethical issues were more 
accessible than the philosophical one in the sense of being both more familiar to the students and easier to form opinions on in the absence of technical knowledge. Most students had previously encountered the ideas of implanting animal organs in humans, altering the characteristics of organisms by manipulating their genes, terminating pregnancies and punishing crimes by death; and whether they had encountered them before or not, they had fairly immediate intuitions about the rights and wrongs of such practices. This enabled them to find substantive areas of disagreement quickly and begin the process of articulating and critiquing their own and others' positions. The problem of free will and determinism, by contrast, was much less familiar to the students and is a controversy on which it is difficult to form an opinion without some understanding of the surrounding philosophical debate.

\section{Strong and Diverse Views among Discussants}

One factor identified by many of the teachers and students we spoke to as being highly conducive to discussion was diversity of views among students. While it is possible, and sometimes desirable, to create an artificial diversity of views by asking students to defend views they do not in fact hold, it was generally felt by our participants that genuine differences of opinion in a class helped enormously in generating worthwhile discussion. As one student succinctly put it:

It's good if people have, like, a difference of opinion, 'cos then you have something to talk about.

One teacher considered that the greatest obstacle he faced in his efforts to facilitate discussion with his current class was a certain homogeneity of outlook:

I think it's quite difficult when you have, as I've got this year, a much more homogenous group who largely, at least at a superficial level, kind of think the same sort of things.

In addition to the need for a diversity of student views, many participants thought the quality of class discussion was significantly enhanced by students holding their views strongly or passionately. One reason given for this was simply that discussions are more interesting and dynamic when animated by a bit of passion. Another was that students tend to be more ready and better able to advance arguments for positions they feel strongly about. One student expressed the latter point like this:

I feel that if I'm more passionate about something, I'm more willing to sort of put my point across more and sort of argue it more, because if I'm more passionate about it I often have more, like a stronger opinion about it. So I've thought about it more and know more about it so then I can argue more and reinforce my arguments more.

Possibly related to the idea that discussion is enhanced by passionately-held views is the idea that it is enhanced by extreme ones. Some such connection is implied by the following student assessment of what makes for a good discussion:

It sometimes makes it more interesting if you've got two people who are passionately on opposite sides of the argument, or someone who can argue passionately for one side 
or the other. Not just because it makes it a bit more forceful, but you can sort of then get wider ends of the spectrum and try and work out where you're going to fit in.

Passionately-held views, this student plausibly suggests, tend to be located at the ends of spectra: extreme positions, perhaps, need more passion to sustain them than moderate ones. Be that as it may, the advantage this student sees in having extreme views articulated and defended in discussion is interesting. What this can do, he thinks, is stake out the disputed territory in a way that is helpful to the undecided in their efforts to 'work out where you're going to fit in'.

Other participants too commented on the value of extreme student views. Here are two teachers discussing what is needed for a good quality discussion:

Teacher A: But it does require a few key personalities as well.

Teacher B: You do need a couple of crackpots, definitely. Nothing really gets a conversation started better than that, when somebody just says something so off the wall, and you can count on one or two of them to do that this year.

These three factors-diversity of student views, passionately-held student views and extreme student views - were all present in the most successful of the discussions we observed. The exemplary discussion of xenotransplantation, for example, was driven by two powerful central figures, one passionately and unambiguously committed to the view that xenotransplantation is entirely unobjectionable, the other determined to ensure a fair hearing for a range of possible moral objections. Although their voices were dominant, these two did not exclude or drown out other participants, and their contributions could plausibly be seen as staking out the ethical terrain in a way that allowed others to start working out where they stood. It is difficult to see how this discussion could have been as dynamic, critical and fruitful as it was without the presence of diverse views, passionately-held views and extreme views. Our observations therefore supported the claims of our interviewees that these three factors serve to promote high quality discussion.

\section{Appropriate Facilitation}

We have argued that, for genuine discussion to occur, students must recognise that the question they are discussing is an open one, a question to which their teacher does not know the right answer. But it does not follow from this that the roles of teacher and student in class discussion are indistinguishable. All of the students we interviewed spoke positively about the significant role played by their teachers in facilitating and advancing discussion. In its most interventionist form, this involved the imposition of a systematic structure on discussion to ensure that rival views were properly examined. One student reported:

... we outline the argument and then we look and analyse each argument and the counter arguments ... it is a bit systematic but it really makes you think about what he's actually saying rather than just throwing your own view in there without really 
understanding what you're actually fighting against, and so ... you've gone through it logically and then you go on to form your opinion. I think it works really well like that.

More commonly, teachers took on the role of critical questioner, responding to views expressed by students with requests for elaboration and justification:

I think one of the things that I try to do, perhaps at the beginning of the course-it's hard for the students to do it-is to get them to actually think through and explain why they make a statement because they are always very quick to come out with 'I think this or that' or 'that's rubbish' or something like that, but without knowing perhaps why they've arrived at that view for themselves.

As classes became more adept at discussion, learning to think systematically about conflicting opinions and to ask critical questions of one another, teachers were able to adopt a progressively lighter touch. In one POS centre the teacher sometimes needed to do little more than start the ball rolling:

[Teacher's name] would start us off on a debate and then we develop our ideas and ... he'd leave it to us to decide who would speak when, and so I think that worked better because that made you think more about how to have a discussion, taking people's points of view as well as like developing your point of view and listening to what they have to say.

What constituted appropriate facilitation, then, was determined in large part by the degree to which students had acquired the skills and virtues of discussion. While the students evidently valued the freedom afforded by discussion to raise and explore ideas on their own terms, they regarded this as quite compatible with active facilitation of discussion by teachers.

The few discussions we witnessed from which the teacher was entirely absent involved markedly lower levels of argument and analysis. The discussions were animated enough, and elicited contributions from most participants, but they rarely progressed beyond the stating and restating of opinions. Without a teacher in the critical questioning role, students seemed disinclined to offer arguments for their views and reticent about pressing others to justify theirs.

\section{Impediments to Discussion}

There are two sorts of move sometimes made by students in class discussion, particularly discussion of ethical issues, which threaten to block or stall it. The moves do not necessarily have this effect, but we think they represent significant enough dangers to warrant attention.

The first we call the that's-just-what-I-believe move. It is not uncommon for participants in a discussion, especially when backed into a corner, to reassert their opinion with a rider along the lines of 'that's just what I believe'. The effect of this rider is to reclassify the opinion from the category of provisional views that I am willing and able to change in light of relevant reasons to the category of fixed and immutable features of my being. 
What I believe on this matter is just part of who I am. The danger of allowing students to get away with this move is that it permits them to construe any further attack on the opinion in question as an attack on their identity.

We saw this move made by students in two of the discussions we observed. In one, a small group discussion of capital punishment without a teacher present, the move brought the discussion to an abrupt and premature end:

Student A: If your Dad killed someone, you'd still want him there. You wouldn't want him dead.

Student B: So? It's just people's opinions, isn't it?

Student A: It can't be different for everyone apart from your Dad!

Student B: (Talking over student $A$ ) This whole argument's useless. It's just people's opinions.

(Long silence)

Student C: So, shall we just ... end it there?

The other discussion in which we saw the move made was a teacher-led class discussion on the topic of abortion. On this occasion, the teacher managed to sidestep the danger and proceed with the discussion:

Teacher: What about if the child was a product of rape? Would the mother's right outweigh the baby's right there, or would you disagree with that?

Student: I personally think it would, but it's a personal matter of what you believe in.

Teacher: Why do you think it would? What is it about the situation that you think it would?

Student: I guess it would depend on how the mother treats the child when it's born as well. It's not her fault, so it's not a choice that she's made.

Prior to this exchange, the weight of opinion in the class has been leaning towards the view that the unborn child's right to life trumps the mother's right to choose. So when the student finds herself wanting to defend the mother's right to choose in the scenario suggested by the teacher, she is conscious of taking a position apparently at odds with those of her classmates. This may well be the reason for her attempt to insulate her opinion from criticism by classifying it as 'a personal matter of what you believe in'.

The teacher, to her credit, refuses to accept-or, more precisely, simply ignores - the student's attempt at reclassification. She continues to treat the opinion as the sort of thing for which the student should be able to produce reasons, and should be willing to give up if she cannot produce reasons. And, as it turns out, the student is able to produce a rather good reason for differentiating between pregnancies that are a consequence of rape and those that are not: in the former case, but not the latter, the mother is absolved of responsibility for becoming pregnant, and therefore of responsibility for the life of the unborn child.

The second move that threatens to block discussion is the that's-what-my-religion-says move. In some ways the second move resembles the first: it can have the effect of shifting an opinion from the domain of public disputation to the domain of personal identity. But it can also have another, rather different effect: that of reducing a wide range of 
interesting and complex ethical disagreements to a single and intractable disagreement about the existence of God. We did not see this move made in the discussions we observed, but one group of students reported that their discussions became bogged down quite often in heated conflicts between theists and atheists:

Student A: It was yelling views over and over again.

Student B: It becomes more like anger instead of reasoning.

Student C: It was more emotion. It wasn't really ...

Interviewer: Tell us about that. Give us an example.

Student D: Religion is a big one. Some people-I'm not going to name namesare quite religious, including myself, and so when people were like 'God doesn't exist' and stuff like that, some people were like 'That's not true!' 'But that's your opinion - it's not my opinion!' Some people use that as a cause of their debates, as it were: 'It's God's right', 'You can't kill anyone', 'Euthanasia is wrong', and stuff like that ...

Student A: It was about learning how to argue and the arguments would deteriorate, just before you get down to 'I'm right, you're wrong' and just yelling at each other...

Student B: Some people don't really acknowledge why those people have that particular point of view-for instance an atheist might not see why this person would believe in God and totally not acknowledge it, I mean their reasonings — and that's when discussions tend to be getting out of hand.

We do not mean to suggest that the existence of God is an inappropriate topic for class discussion, or to deny that some ethical disputes have a theological foundation. But it is all too easy for students with basic religious disagreements to ignore or distort important ethical arguments in their haste to reach familiar religious territory and resume entrenched positions in a sterile theological war.

Nor do we mean to imply that religious disagreements among students are necessarily detrimental to discussion. On the contrary, some of the teachers and students we spoke to saw religious diversity as increasing students' interest and engagement in the discussion of ethical issues. One teacher said:

I mean, we have a lot of students who hold either very Christian views or alternative religious views and that has fuelled discussion very much because it is a deep-seated belief for them, so yes it certainly can sort of get things going. And not everybody necessarily agrees with coming from that point of view so it does sort of help to, you know, get a bit of back and forth.

\section{Conclusion}

To sum up: Participating in discussion involves attending to multiple points of view, being receptive or responsive to opinions other than one's own, and being concerned to develop one's knowledge or understanding. The case for teaching controversial issues by means of discussion is, first, that discussion is peculiarly conducive to appreciative understanding of the different positions in a controversy, and, second, that controversial 
issues are the one area of the curriculum in which teachers can engage students in discussion. Discussions of controversial issues in schools and colleges tend to be helped by effective preparation, accessible topics, strong and diverse views among discussants, and appropriate facilitation, and to be hindered by discussants making the that's-justwhat-I-believe move and the that's-what-my-religion-says move.

There is, of course, some variation in the degree to which the helps and hindrances we have identified are under the teacher's control. The teacher can prepare her students for discussion, select topics that are likely to be accessible to them, and facilitate discussion as actively or passively as she deems appropriate; but she cannot determine the strength or diversity of students' views on a topic, or prevent students from making discussionstalling moves. It does not follow, however, that awareness of the latter factors has no pedagogical value. While discussion-stalling moves are not easily prevented, a teacher conscious of the threat they pose can be ready to intervene when they occur to put discussion back on track. And a teacher who recognises the value for discussion of strong and diverse student views can spend some time trying out different topics with her class and identifying the ones most likely to elicit passion and disagreement. Given that the point of discussing controversial issues in the classroom has as much to do with initiating students into the practice of discussion as it does with developing students' understanding of particular issues, there is a strong case for giving disproportionate attention to topics that genuinely divide the class.

\section{Acknowledgements}

The authors would like to thank Ruth Amos for her assistance on the empirical study reported here, and the Science Education Group at the University of York for funding the study.

\section{References}

Arnold, M. (1869) [1960] Culture and Anarchy, J. Dover Wilson, ed. (Cambridge, Cambridge University Press).

Bridges D (1979) Education, Democracy and Discussion (Slough, NFER).

Brookfield, S. D. \& Preskill, S. (1999) Discussion as a Way of Teaching (Buckingham, SRHE and Open University Press).

Cam, P. (1995) Thinking Together: Philosophical Inquiry for the Classroom (Sydney, Hale and Iremonger/PETA).

Carrington, B. \& Troyna, B. (eds) (1988) Children and Controversial Issues (London, Falmer).

CitizEd (2004) Teaching Controversial Issues: Briefing Paper for Trainee Teachers of Citzenship Education (London, CitizEd).

Citizenship Foundation (2003) Teaching About Controversial Issues: Guidance for Schools (London, Citizenship Foundation).

Claire, H. \& Holden, C. (2007) The Challenge of Teaching Controversial Issues (Stoke-on-Trent, Trentham).

Countryside Foundation for Education (CFE) (2002) Handling Controversial Issues in the Classroom (Hebden Bridge, Countryside Foundation for Education).

Dearden, R. F. (1981) Controversial Issues and the Curriculum, fournal of Curriculum Studies, 13.1, pp. 37-44.

Development Education Association (DEA) (2001) Citizenship Education: The Global Dimension (London, Development Education Association). 
Dewhurst, D. W. (1992) The Teaching of Controversial Issues, fournal of Philosophy of Education, 26.2, pp. 153-163.

Gardner, P. (1984) Another Look at Controversial Issues and the Curriculum, Fournal of Curriculum Studies, 16.4, pp. 379-385.

Geddis, A. (1991) Improving the Quality of Science Education Classroom Discourse on Controversial Issues, Science Education, 75.2, pp. 169-183.

Hand, M. (2007) Should We Teach Homosexuality as a Controversial Issue? Theory and Research in Education, 5.1, pp. 69-86.

Hand, M. (2008a) What Should We Teach as Controversial? A defence of the epistemic criterion, Educational Theory, 58.2, pp. 213-228.

Hand, M. (2008b) Can Children be Taught Philosophy? in: M. Hand \& C. Winstanley (eds), Philosophy in Schools (London, Continuum).

Hess, D. (2002) Teaching Controversial Public Issues Discussions: Learning from skilled teachers, Theory and Research in Social Education, 30.1, pp. 10-41.

Hess, D. (2004) Controversies about Controversial Issues in Democratic Education, PS: Political Science and Politics, 37, pp. 257-261.

Kelly, T. (1986) Discussing Controversial Issues: Four perspectives on the teacher's role', Theory and Research in Social Education, 14.2, pp. 113-138.

Learning and Skills Development Agency (LSDA) (2005) Agree To Disagree: Citizenship and Controversial Issues (London, Learning and Skills Development Agency).

Levinson, R. (2001) Should Controversial Issues in Science be Taught Through the Humanities? School Science Review, 82.300, pp. 97-102.

Levinson, R. (2006) Towards a Theoretical Framework For Teaching Controversial Socio-Scientific Issues, International fournal of Science Education, 28.10, pp. 12011224.

Lipman, M. (1988) Philosophy Goes to School (Philadelphia PA, Temple University Press).

Lipman, M. (1991) Thinking in Education (New York, Cambridge University Press).

McCall, C. C. (2009) Transforming Thinking: Philosophical inquiry in the primary and secondary classroom (London, Routledge).

Murris, K. \& Haynes, J. (2000) Storywise: Thinking through stories (Newport, Dialogue Works).

Myhill, D. (2007) Reading the World: Using children's literature to explore controversial issues, in: H. Claire \& C. Holden (eds), The Challenge of Teaching Controversial Issues (Stoke-on-Trent, Trentham).

Oulton, C., Day, V., Dillon, J. \& Grace, M. (2004a) Controversial Issues-Teachers' Attitudes and Practices in the Context of Citizenship Education, Oxford Review of Education, 30.4, pp. $489-507$.

Oulton, C., Dillon, J. and Grace, M. (2004b) Reconceptualising the Teaching of Controversial Issues, International Fournal of Science Education, 26.4, pp. 411-423.

Oxfam (2006) Teaching Controversial Issues (Oxford, Oxfam).

Qualifications and Curriculum Authority (QCA) (2001) Citizenship Scheme of Work for Key Stage 3: Teacher's Guide (London, Qualifications and Curriculum Authority).

Rudduck, J. (1986) A Strategy for Handling Controversial Issues in the Secondary School, in J. J. Wellington (ed.), Controversial Issues in the Curriculum (Oxford, Blackwell).

Runnymede Trust (2003) Complementing Teachers (London, Runnymede Trust).

Solomon, J. (1990) Discussion of Social Issues in the Science Classroom, Studies in Science Education, 18, pp. 105-126.

Solomon, J. (1992) The Classroom Discussion of Science-Based Social Issues Presented on Television: Knowledge, attitudes and values, International fournal of Science Education, 14.4, pp. 431-444.

Splitter L. J. \& Sharp, A. M. (1995) Teaching for Better Thinking: The Classroom community of inquiry (Melbourne, ACER).

Stenhouse, L. (1969) Handling Controversial Issues in the Classroom, Education Canada, 9.4, pp. 12-21. 
Stradling, R., Noctor, M. \& Baines, B. (eds) (1984) Teaching Controversial Issues (London, Edward Arnold).

Taylor, J. L. \& Swinbank, E. (2007) Designing a Course that Promotes Debate: The Perspectives on Science (POS) AS level model, School Science Review, 88.324, pp. 41-48.

TeacherNet (2006) Racist Bullying. Available at: www.teachernet.gov.uk/wholeschool/behaviour/ tacklingbullying/racistbullying (accessed 26 August 2006).

Thomas, J. (2000) Using Current Controversies in the Classroom: Opportunities and concerns, Melbourne Studies in Education, 41.2, pp. 133-144.

Wellington, J. J. (ed) (1986) Controversial Issues in the Curriculum (Oxford, Blackwell). 